\title{
ASSESSMENT ON THE OPTIMUM PERFORMANCE OF A NOVEL 3 AXES MICRO EDM DEVELOPED FOR COMMERCIAL APPLICATIONS
}

\author{
SURESH P1, VENKATESH RAJA K ${ }^{2}$ \\ ${ }^{I}$ Sona College of Technology, Department of Mechatronics Engineering, Salem - 636 005, Tamil Nadu, \\ India, $e$ - mail: suresh_p_g@yahoo.com \\ ${ }^{2}$ Sona College of Technology, Department of Mechanical Engineering, Salem - 636005 , Tamil Nadu, \\ India, e-mail: kvenkateshraja@hotmail.com
}

\begin{abstract}
A low cost three axes commercial microEDM machine has been developed indigenously in order to implement precision micromachining. The developed microEDM consists of various components such as machining chamber, X-Y table, tool feed and tool holder assembly, dielectric circulation system, power supply and automatic driving devices to control the spark gap distance. The setup is capable of performing the $8 \mu \mathrm{m}$ movement in Z-axis.The developed 3 axes machine and the commercial available machine are investigated with the most important process parameters such as Current, Pulse on time and Pulse off time in order to study the Material Removal Rate (MRR) and Tool Wear Rate (TWR). The material chosen for the current research is Stainless Steel 316L, which has high corrosion resistance and the electrode was tungsten $300 \mu \mathrm{m}$. In most of the experiments, the developed machine has performed with $6.52 \%$ higher MRR and $26.10 \%$ Lower TWR. This is due to the effective spark gap circuit developed with the use of hall current sensor.The mathematical model of MRR and TWR are obtained by correlating the process parameter using Response Surface Methodology (RSM).The chosen objectives are contradictory in nature, we employ a non-dominated Genetic algorithm to find the optimal process parameters. The developed 3 axes microEDM has yield a $10.14 \%$ and $33.12 \%$ better performance on optimum maximum MRR and minimum TWR respectively when compared to the commercial machine.
\end{abstract}

KEYWORDS: Material Removal Rate, Tool Wear Rate, Multi-objective Optimization, Genetic Algorithm, 3 axes microEDM

\section{Introduction}

As the developments in the process of miniaturization, new fields are evolving which have a need for micro fabricated components. To meet the demands of such applications like biotechnology, microsurgery and high temperature environments, special harder materials are required. The microEDM is a reasonable alternative that provides the necessary accuracy as well as economic production capability. In microEDM, controlled sparking is used to remove material.

Mahendran et al [1] clearly described the micro Electric Discharge Machining ( $\mu$ EDM) principles, EDM processes types, dielectric fluids, electrodes, tool feed control and process parameters for MRR and TWR. Richard and Demellayer [2] developed a $\mu$ EDM milling setup in order to eliminate the cutting force. Bragança et al [3] presented a study of the $\mu$ EDM process, using an innovative in-house prototype machine that creates single point-to-plane spark discharges. Karthikeyan et al [4] conducted general factorial experiments for $\mu$ EDM in order to present an exhaustive study of parameters on the MRR and TWR. Kibria et al[5] studied the performance of various dielectric fluids like kerosene, deionized water, boron carbide powder suspended kerosene and deionized water on the machining performance ofTi6Al-4V alloy. Dhanabalan et al [6] optimized the machining process parameters namely the 
peak current, pulse on time and pulse off time of two dissimilar titanium grades with brass electrode in EDM. Kadirvel et al [7] have performed machining on EN24 die steel using copper, tungsten, copper tungsten, and silver tungsten electrodes in $\mu$ EDM. They have analyzed the performance of MRR, circularity, overcut and heat-affected zones of micro machined holes.Pay Liew et al [8] have applied ultrasonic vibration by a probe type vibrator to dielectric fluid to assist machining of deep micro holes in ceramic materials in $\mu \mathrm{EDM}$. Sabur et al [9] have studied the effect of $\mu$ EDM parameters voltage and capacitance on MRR of nonconductive $\mathrm{ZrO}_{2}$ ceramisc. Kung et al [10] introduced a powder mixed EDM while machining cobalt-bonded tungsten carbide. The RSM is used to plan and analyze the experiments in terms of MRR and EWR. Durillo et al [11] conducted experiments to compare the Multi-Objective Particle Swam Optimization (MOPSO) with the NSGA II. Somashekhar et al [12] studied the MRR in the $\mu$ EDM process using feed forward ANN with back propagation algorithm along with the GA that can synthesize optimum input conditions to maximize the MRR. Mohamad et al [13] optimized the surface roughness of EDM with input process parameters like pulse on time, duty factor and discharge current using Taguchi method and ANOVA. Pushpendra et al [14] developed the ANN model for the experimental values and then applied NSGA II algorithm to predict the MRR and surface roughness for Inconol 718 with copper as tool electrode. Shankar and Mishra [15] clustered and ranked the obtained optimal solutions from the Pareto-optimal front obtained using NSGA-II. Few other works pertaining to EDM were also reported with regards to optimization and parametric investigation $[18,19,20]$.

From the literature, it is clear that the most of the researchers have developed the experimental setup and studied the performance of microEDM. However, further studies are required to improve the microEDM process parameters and commercialize the technology at a lower cost. Considering these requirements, a 3 axes microEDM setup to be developed and various process parameters like current, pulse on time and pulse off time on MRR and TWR are to be studied. In addition, from the literature, it can be inferred that most of the researchers have not dealt with SS 316L in microEDM domain. Therefore, in the current research the SS $316 \mathrm{~L}$ material is used to study the performance.

\section{Experimental Plan}

The stainless steel 316L (SS316L) which is considered in this experiment is used in pharmaceuticals, marine and medical applications, due to various mechanical properties, namely high oxidation resistance, corrosion resistance and hardness. The chemical composition of the SS316L is given in the Table 2.1.

Table 2.1 Composition of stainless steel 316L

\begin{tabular}{|c|c|c|c|c|c|c|c|c|c|}
\hline Elements & $\mathrm{C}$ & $\mathrm{Mn}$ & $\mathrm{Si}$ & $\mathrm{P}$ & $\mathrm{S}$ & $\mathrm{Cr}$ & $\mathrm{Mo}$ & $\mathrm{Ni}$ & $\mathrm{N}$ \\
\hline Percentage & 0.03 & 2.0 & 0.75 & 0.045 & 0.03 & 18.0 & 3.00 & 14.0 & 0.10 \\
\hline
\end{tabular}

Taguchi method is an influential method that provides an easy, competent and organized approach to compute the optimum process parameters, which significantly diminish the number of experiments that are required to model response functions [16]. The major influencing process parameters and their levels considered are listed in Table 2.2. The MRR and TWR are calculated on the loss of weight of the work piece after the machining and dividing with the machine time. The SHIMADZU electronic balance having a resolution of $0.001 \mathrm{~g}$ is used to measure the initial and final weight of the tool as well as the work piece. The machining time taken for each micro hole is measured using stopwatch. The table 2.3 
shows the data has chosen for conducting the experiments on both developed as well as on the commercial machine.

Table 2.2 Machining parameters and their levels

\begin{tabular}{|l|c|c|c|}
\hline \multicolumn{1}{|c|}{ Parameters } & Level 1 & Level 2 & Level 3 \\
\hline Discharge current $[\mathrm{A}]$ & 6 & 9 & 12 \\
\hline Pulse on time $[\mu \mathrm{s}]$ & 3 & 6 & 9 \\
\hline Pulse off time $[\mu \mathrm{s}]$ & 3 & 6 & 9 \\
\hline
\end{tabular}

Table 2.3Data has chosen for conducting the experiments

\begin{tabular}{|l|c|}
\hline Diameter of specimen & $50 \mathrm{~mm}$ \\
\hline Thickness of specimen & $2 \mathrm{~mm}$ \\
\hline Electrode & Tungsten \\
\hline Electrode diameter & $300 \mu \mathrm{m}$ \\
\hline Dielectric medium & de-ionized water \\
\hline
\end{tabular}

\subsection{Experiments Using Electronica die Sinking Commercial microEDM}

Experiments are conducted on Electronica die Sinking Commercial microEDM (Figure 2.1) using the machining parameters and data listed in the table 2.2 and 2.3 respectively. The results are presented in Table 2.4. In order to predict the objectives, a second-order mathematical model is selected in Response Surface Methodology (RSM). The experimental values are analyzed using the Design Expert 7.0. The multiple regression coefficients R2 of MRR and TWR models are found to be 0.9827 and 0.9691 respectively, which shows the model is best fitted. The following mathematical model for MRR and TWR are given in equation 2.1 and 2.2 respectively.

Table 2.4 Experimental results - Electronica die Sinking Commercial microEDM

\begin{tabular}{|c|c|c|c|c|c|c|}
\hline Ex. No & $\begin{array}{c}\text { Current } \\
(\mathrm{A})\end{array}$ & $\begin{array}{c}\text { Pulse on time } \\
(\mu \mathrm{s})\end{array}$ & $\begin{array}{c}\text { Pulse off time } \\
(\mu \mathrm{s})\end{array}$ & $\begin{array}{c}\text { Machining } \\
\text { time }(\mathrm{sec})\end{array}$ & $\begin{array}{c}\text { MRR } \\
(\mu \mathrm{g} / \mathrm{s})\end{array}$ & $\begin{array}{c}\text { TWR } \\
(\mu \mathrm{g} / \mathrm{s})\end{array}$ \\
\hline 1 & 6 & 3 & 3 & 710 & 2.6761 & 3.9437 \\
\hline 2 & 6 & 3 & 6 & 680 & 2.9412 & 3.6765 \\
\hline 3 & 6 & 3 & 9 & 645 & 2.6357 & 3.5659 \\
\hline 4 & 6 & 6 & 3 & 650 & 2.7692 & 4.7692 \\
\hline 5 & 6 & 6 & 6 & 610 & 3.1148 & 3.7705 \\
\hline 6 & 6 & 6 & 9 & 535 & 4.1121 & 4.1121 \\
\hline 7 & 6 & 9 & 3 & 585 & 3.0769 & 4.7863 \\
\hline 8 & 6 & 9 & 6 & 520 & 3.4615 & 5.1923 \\
\hline 9 & 6 & 9 & 9 & 474 & 4.2194 & 5.4852 \\
\hline 10 & 9 & 3 & 3 & 552 & 3.2609 & 4.1667 \\
\hline
\end{tabular}




\begin{tabular}{|c|c|c|c|c|c|c|}
\hline 11 & 9 & 3 & 6 & 490 & 3.4694 & 4.2857 \\
\hline 12 & 9 & 3 & 9 & 512 & 3.7109 & 4.2969 \\
\hline 13 & 9 & 6 & 3 & 525 & 3.4286 & 4.1905 \\
\hline 14 & 9 & 6 & 6 & 462 & 4.7619 & 3.8961 \\
\hline 15 & 9 & 6 & 9 & 410 & 4.1463 & 4.8780 \\
\hline 16 & 9 & 9 & 3 & 496 & 3.4274 & 6.2500 \\
\hline 17 & 9 & 9 & 6 & 430 & 4.1860 & 6.2791 \\
\hline 18 & 9 & 9 & 9 & 357 & 5.8824 & 6.7227 \\
\hline 19 & 12 & 3 & 3 & 321 & 6.5421 & 7.7882 \\
\hline 20 & 12 & 3 & 6 & 275 & 7.6364 & 7.6364 \\
\hline 21 & 12 & 3 & 9 & 290 & 7.5862 & 6.8966 \\
\hline 22 & 12 & 6 & 3 & 290 & 6.8966 & 8.6207 \\
\hline 23 & 12 & 6 & 6 & 255 & 8.2353 & 8.6275 \\
\hline 24 & 12 & 6 & 9 & 220 & 8.1818 & 7.7273 \\
\hline 25 & 12 & 9 & 3 & 255 & 7.4510 & 12.1569 \\
\hline 26 & 12 & 9 & 6 & 230 & 9.1304 & 11.3043 \\
\hline 27 & 12 & 9 & 9 & 210 & 10.4762 & 13.3333 \\
\hline & & & & & & \\
\hline
\end{tabular}

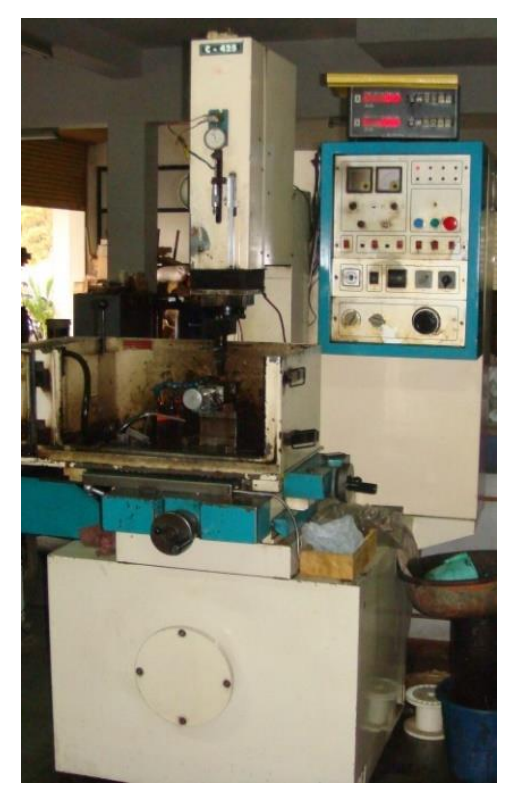

Fig. 2.1 Electronica Die sinking Commercial microEDM Machining Setup

$$
\begin{aligned}
M R R= & 12.69633088-2.695085999 * x(1)-0.353832377 * x(2)- \\
& 0.066685171 * x(3)+0.025814814 * x(1) * x(2)+0.026940924 * \\
& x(1) * x(3)+0.047859338 * x(2) * x(3)+0.176513152 * x(1) * \\
& x(1)+0.002943063 * x(2) * x(2)-0.020951094 * x(3) * x(3)
\end{aligned}
$$




$$
\begin{aligned}
T W R= & 21.41862699-3.439792881 * x(1)-1.804055726 * x(2)- \\
& 0.487090827 * x(3)+0.094403945 * x(1) * x(2)-0.002524187 * \\
& x(1) * x(3)+0.032289254 * x(2) * x(3)+0.206552518 * x(1) * \\
& x(1)+0.102362321 * x(2) * x(2)+0.026873318 * x(3) * x(3)
\end{aligned}
$$

\subsection{Experiments Using Developed 3 axes microEDM}

Experiments are conducted on the developed 3 axes microEDM (Figure 2.2) using the

\begin{tabular}{|c|c|c|c|c|c|c|}
\hline Ex. No & Current (A) & $\begin{array}{l}\text { Pulse on } \\
\text { time }(\mu s)\end{array}$ & $\begin{array}{l}\text { Pulse off } \\
\text { time }(\mu s)\end{array}$ & $\begin{array}{l}\text { Machining } \\
\text { time (sec) }\end{array}$ & $\begin{array}{l}\text { MRR } \\
(\mu \mathrm{g} / \mathrm{s})\end{array}$ & $\begin{array}{l}\text { TWR } \\
(\mu \mathrm{g} / \mathrm{s})\end{array}$ \\
\hline 1 & 6 & 3 & 3 & 768 & 2.9948 & 2.8646 \\
\hline 2 & 6 & 3 & 6 & 750 & 3.0667 & 2.9333 \\
\hline 3 & 6 & 3 & 9 & 681 & 3.0837 & 3.6711 \\
\hline 4 & 6 & 6 & 3 & 778 & 3.0848 & 2.8278 \\
\hline 5 & 6 & 6 & 6 & 627 & 3.6683 & 3.6683 \\
\hline 6 & 6 & 6 & 9 & 643 & 3.7325 & 3.2659 \\
\hline 7 & 6 & 9 & 3 & 611 & 3.6007 & 4.0917 \\
\hline 8 & 6 & 9 & 6 & 580 & 3.7931 & 4.1379 \\
\hline 9 & 6 & 9 & 9 & 585 & 4.1026 & 4.4444 \\
\hline 10 & 9 & 3 & 3 & 590 & 3.8983 & 3.5593 \\
\hline 11 & 9 & 3 & 6 & 612 & 3.7582 & 3.1046 \\
\hline 12 & 9 & 3 & 9 & 656 & 3.8110 & 3.5061 \\
\hline 13 & 9 & 6 & 3 & 572 & 3.8462 & 3.6713 \\
\hline 14 & 9 & 6 & 6 & 566 & 4.2403 & 3.3569 \\
\hline 15 & 9 & 6 & 9 & 535 & 4.4860 & 5.0467 \\
\hline 16 & 9 & 9 & 3 & 657 & 4.1096 & 4.5662 \\
\hline 17 & 9 & 9 & 6 & 681 & 4.4053 & 4.1116 \\
\hline 18 & 9 & 9 & 9 & 401 & 7.4813 & 5.9850 \\
\hline 19 & 12 & 3 & 3 & 370 & 7.5676 & 8.1081 \\
\hline 20 & 12 & 3 & 6 & 281 & 7.8292 & 6.0498 \\
\hline 21 & 12 & 3 & 9 & 312 & 7.0513 & 7.3718 \\
\hline 22 & 12 & 6 & 3 & 274 & 8.7591 & 8.3942 \\
\hline
\end{tabular}
same machining parameters and data listed in the table 2.2 and 2.3 respectively. The results are presented in Table 2.5.

Table 2.5 Experimental results - Developed 3 axes microEDM 


\begin{tabular}{|c|c|c|c|c|c|c|}
\hline 23 & 12 & 6 & 6 & 272 & 7.7206 & 6.9853 \\
\hline 24 & 12 & 6 & 9 & 267 & 8.9888 & 7.1161 \\
\hline 25 & 12 & 9 & 3 & 292 & 7.1918 & 9.5890 \\
\hline 26 & 12 & 9 & 6 & 251 & 10.3586 & 11.5538 \\
\hline 27 & 12 & 9 & 9 & 232 & 11.2069 & 12.0690 \\
\hline
\end{tabular}

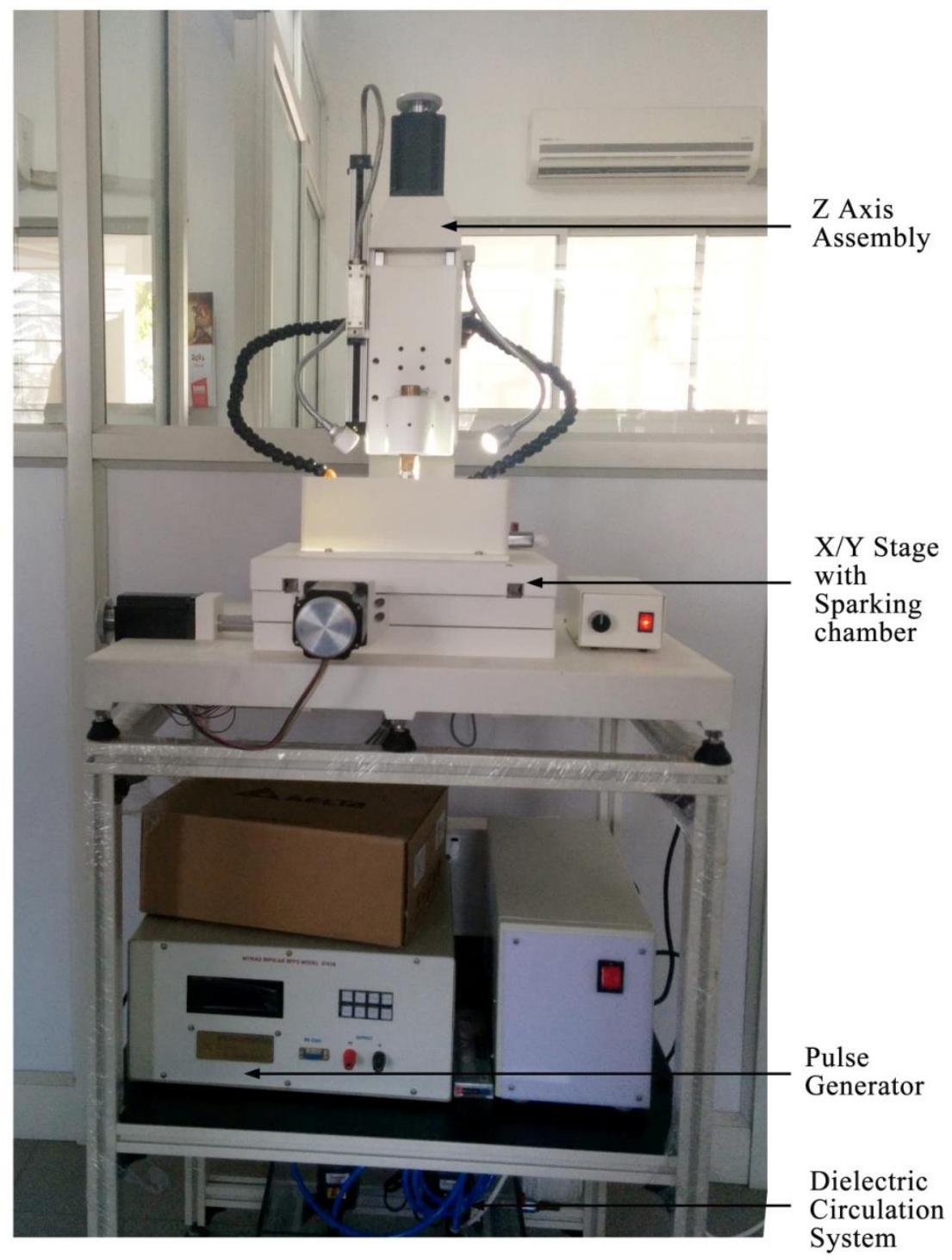

Fig. 2.2 Developed 3 axes microEDM Machining Setup

Similar to above experiment, the RSM is applied and the mathematical model for MRR and TWR are developed and given in the equation 2.3 and 2.4 respectively. The R2 value of the MRR and TWR regression model are $95.49 \%$ and $94.17 \%$ respectively, which mean the model is significant. 


$$
\begin{aligned}
M R R= & +14.95535-2.59574 * x(1)-0.71967 * x(2)-0.60723 * x(3) \\
& +0.036649 * x(1) * x(2)+0.023055 * x(1) * x(3)+0.077810 \\
& * x(2) * x(3)+0.17117 * x(1) * x(1)+0.013935 * x(2) * x(2) \\
& +0.0081268 * x(3) * x(3) \\
T W R= & +20.56830-3.49374 * x(1)-1.54963 * x(2)-0.67014 * x(3)+ \\
& 0.078491 * x(1) * x(2)-0.010481 * x(1) * x(3)+0.039209 * x(2) * \\
& x(3)+0.21806 * x(1) * x(1)+0.080571 * x(2) * x(2)+0.051515 * \\
& x(3) * x(3)
\end{aligned}
$$

\section{Investigation of objectives of commercial machine with developed machine}

In order the study the performance of developed 3 axes microEDM setup, a comparison was made with the commercially available machine. Hence, the same process parameters and their levels have been chosen in the current research. The comparison of MRR and TWR of commercial machine with the developed 3 axes microEDM with different current ranges, pulse on time ranges and pulse off time ranges are plotted and shown in Figure 3.1, 3.2 and 3.3 respectively. The Plots reveals that for all the ranges of the current, pulse on time and pulse off time, the MRR is found to be higher about $6.52 \%$ except in some experiments when compared to that of the commercial machine.In case of TWR it is found to be lower about $26.10 \%$ except in some experiments when compared to that of the commercial machine. This is due the effective spark gap control system, which is developed for the 3 axes microEDM is shown in the figure 3.4. In this circuit, a hall current sensor is implemented to convert the spark gap current into voltage, which is acquired and converted into average voltage. A protocol has been developed to compare this average voltage with the desired pre-set value of gap voltage and accordingly the programme decides the motion of the $\mathrm{Z}$ stage for increasing or decreasing the gap width.

\section{$4 \quad$ Multi-objective genetic algorithm}

Optimization is the process of obtaining the best optimum results under the given circumstance well defined by criteria and constraints. In the real world, engineering problems are usually conflicting in nature, preventing simultaneous optimization of each objective. This optimization leads to better utilization of current, pulse on time and pulse off time. In the current research, the selected objectives MRR and TWR are interrelated but they are contradictory in nature. Since the aim of the research is to increase the MRR and decrease the TWR simultaneously, a multi-objective optimization has been employed to obtain the Paretooptimal solution. GA uses search based algorithm for optimization which are based on the mechanics of natural selection and genetics (Goldberg 1989).The non-dominated sorting genetic algorithm-II (NSGA-II) is unique to solve the multi-objective optimization problem to obtain the optimal process parameters. The algorithm uses non-dominated sorting with crowding distance to find the non-dominated set of values.

The mathematical model is used as a fitness function for the chosen objectives. The multiobjective toolbox in MATLAB 7.8.0 has been used to solve the chosen objectives MRR and TWR, which are accordingly modified as

Objective $1=1 /$ MRR,

Objective 2 = TWR, 
with the boundary values as $6 \leq$ current $\geq 12,3 \leq$ pulse on $\geq 12,3 \leq$ pulse off $\geq 12$. The parameters considered during optimization using the GA multi-objective tool is listed in Table 4.1. The multi-objective optimization has been run on both commercial as well as developed 3 axes microEDM machines to obtain a set of solutions, called Pareto-optimal solution set. The obtained Pareto-optimal front is shown in Figure 4.1, 4.2 and the optimal decision process parameters and their corresponding objective values are listed in Table 4.2, 4.3 respectively.
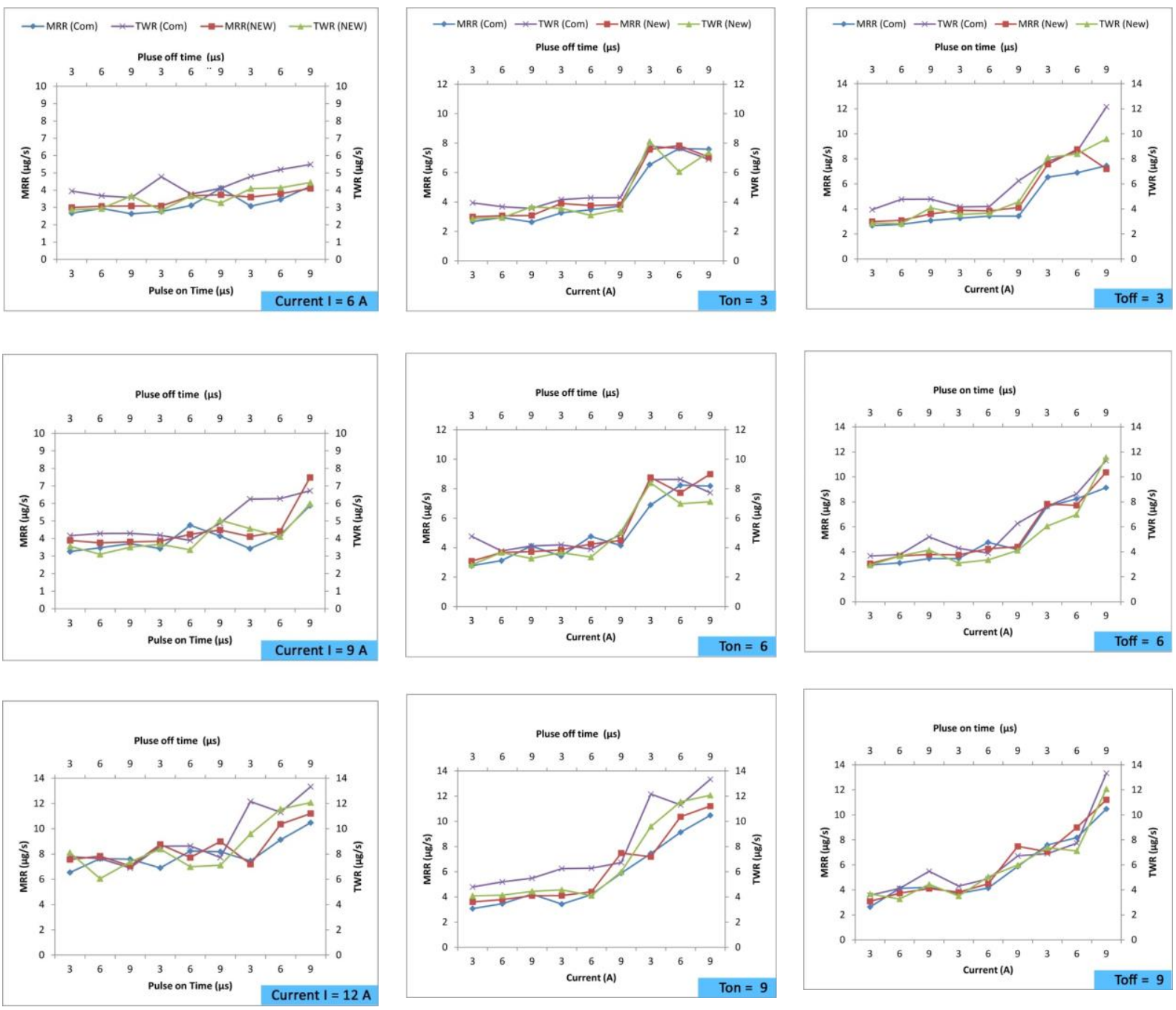

Fig. 3.1 Comparison of MRR and TWR of commercial machine with the developed 3 axes microEDM with different current ranges

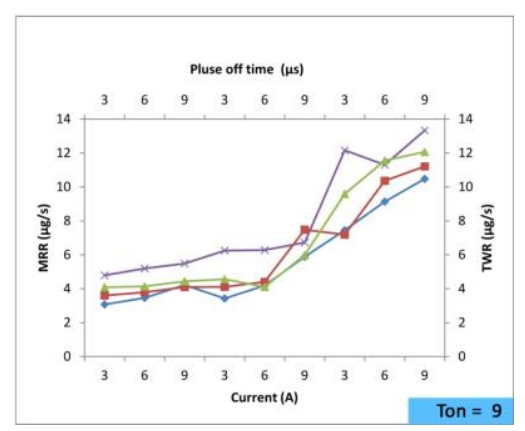

Fig. 3.2 Comparison of MRR and TWR of commercial machine with the developed 3 axes microEDM with different pulse on ranges

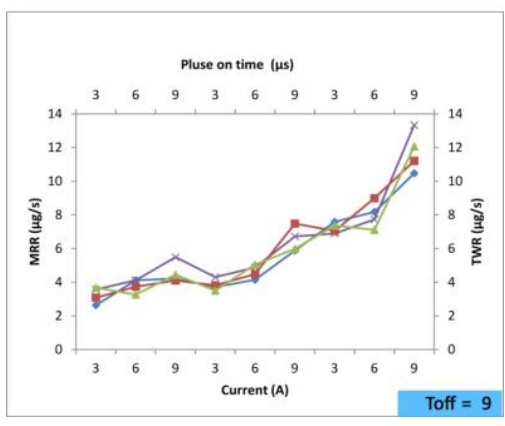

Fig. 3.3Comparison of MRR and TWR of commercial machine with the developed 3 axes microEDM with different pulse off ranges 


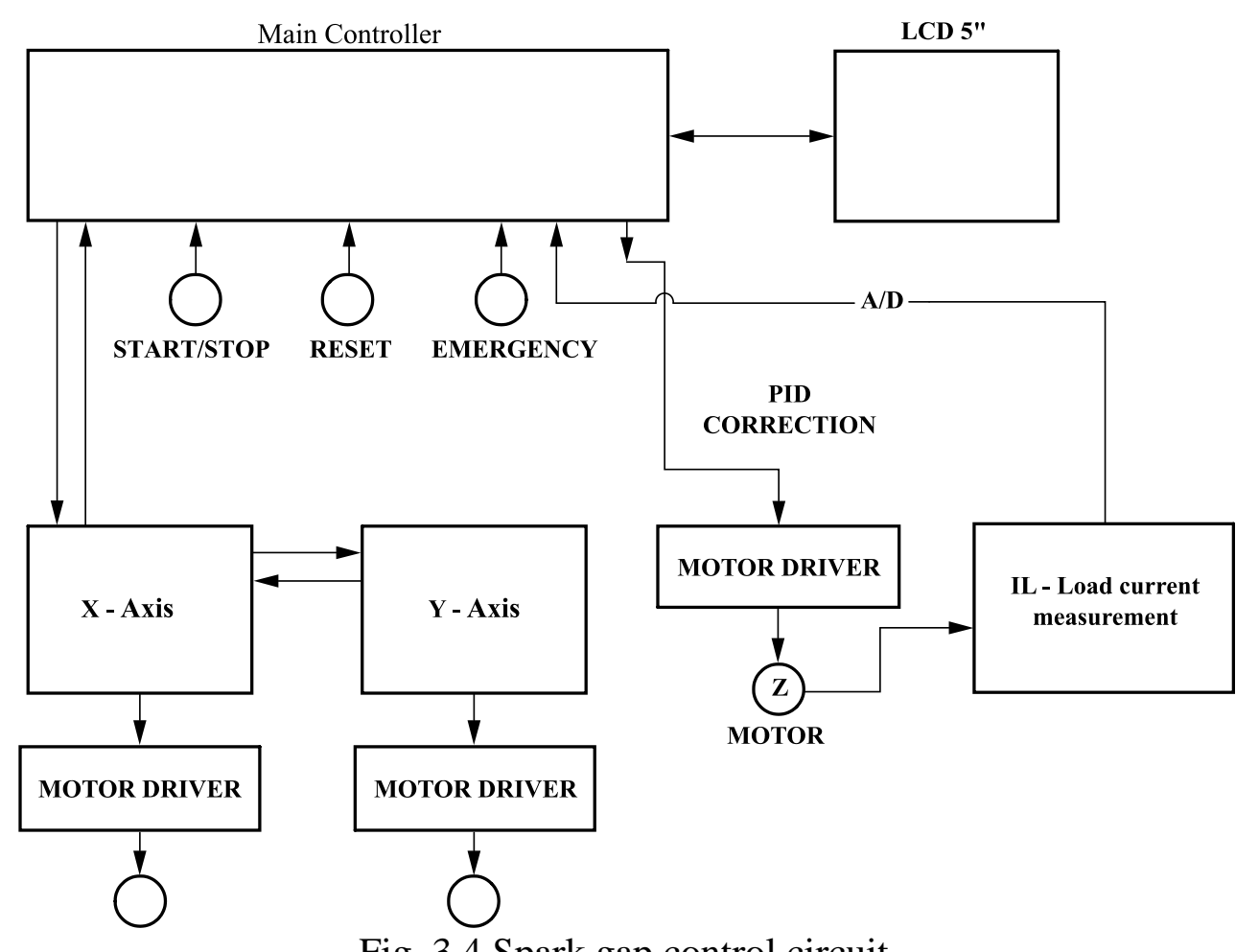

Fig. 3.4 Spark gap control circuit

Table 4.1 MOGA parameters during optimization

Population size

\section{Population type}

Selection function

Tournament size:

crossover fraction

Mutation function

Crossover function

Migration direction

Migration fraction

Migration interval

Distance measure function

Pareto-front population fraction

Mutation rate
Double vector

200

Tournament

2

0.8

Constrained dependent

Scattered

Forward

0.2

20

Crowding

0.5

0.01

From the table 4.2, the commercial microEDM machine has a maximum value of MRR $9.9006 \mu \mathrm{g} / \mathrm{s}$ is obtained under $12.00 \mathrm{~A}$ current, $8.54 \mu \mathrm{s}$ pulse on time and $8.99 \mu$ s pulse off time conditions. The minimum TWR of $3.4976 \mu \mathrm{g} / \mathrm{s}$ is observed at $8.55 \mathrm{~A}, 4.54 \mu \mathrm{s}$ of pulse on time and $7.70 \mu \mathrm{s}$ of pulse off time. Also we observe from the table 4.3, the developed microEDM has a maximum value of MRR $11.0179 \mu \mathrm{g} / \mathrm{s}$ is obtained under $12.00 \mathrm{~A}$ current, $8.97 \mu \mathrm{s}$ pulse on time and $8.99 \mu$ s pulse off time conditions. The minimum TWR of $2.3391 \mu \mathrm{g} / \mathrm{s}$ is observed at $7.28 \mathrm{~A}, 4.74 \mu \mathrm{s}$ of pulse on time and $5.44 \mu \mathrm{s}$ of pulse off time. 


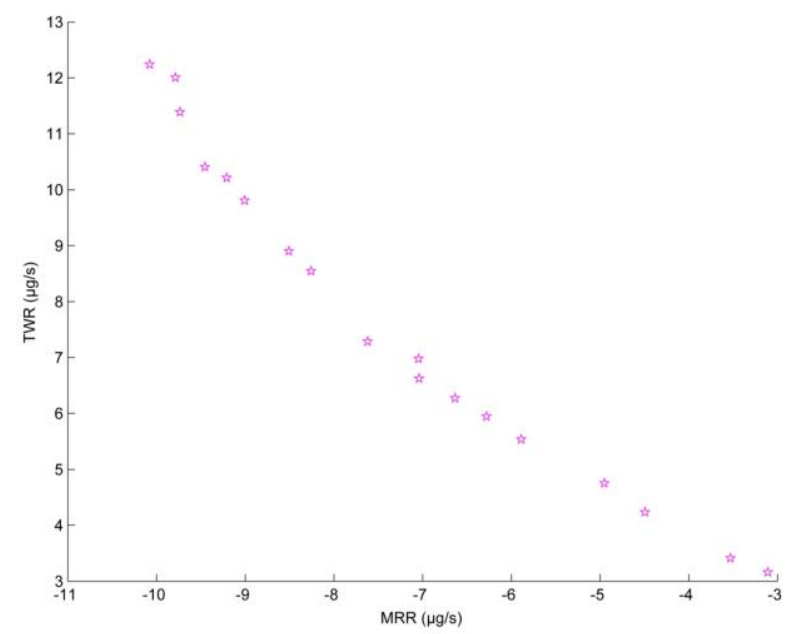

Fig. 4.1 Pareto-optimal front for MRR and TWR of Commercial machine

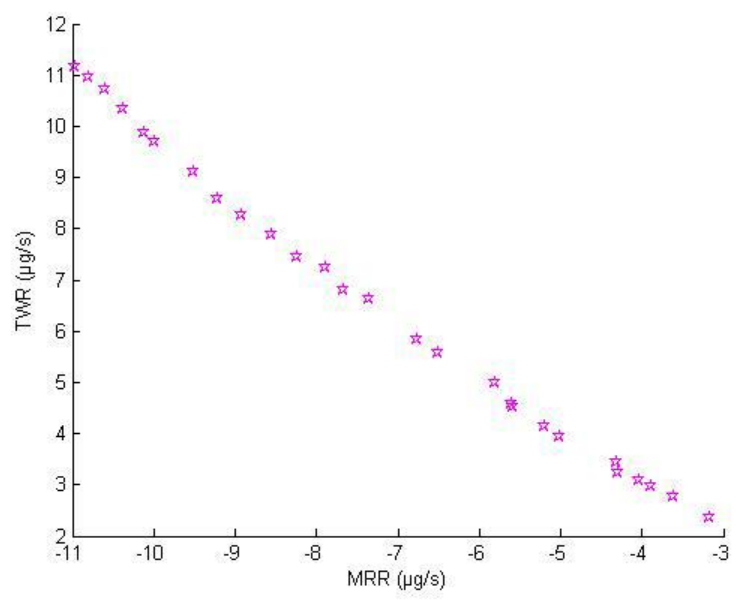

Fig. 4.2 Pareto-optimal front for MRR and TWR of Developed 3 axes microEDM

On comparing the optimum maximum MRR of the developed machinewith the commercial machine, we found the developed machine performs $10.14 \%$ better. Similarly, on comparing the optimum minimum TWR, it performs $33.12 \%$ better.

Table 4.2 A few set optimal decision process parameters and their corresponding objective values of Commercial Machine

\begin{tabular}{|c|c|c|c|c|c|}
\hline S.No & $\begin{array}{c}\text { MRR } \\
(\boldsymbol{\mu g} / \mathbf{s})\end{array}$ & $\begin{array}{c}\text { TWR } \\
(\boldsymbol{\mu g} / \mathbf{s})\end{array}$ & $\begin{array}{c}\text { Current } \\
(\mathbf{A})\end{array}$ & $\begin{array}{c}\text { Pulse on time } \\
(\boldsymbol{\mu s})\end{array}$ & $\begin{array}{c}\text { Pulse off time } \\
(\boldsymbol{\mu s})\end{array}$ \\
\hline 1 & 3.7047 & 3.4976 & 8.55 & 4.54 & 7.70 \\
\hline 2 & 7.3721 & 6.9185 & 11.66 & 4.12 & 8.55 \\
\hline 3 & 9.9006 & 11.6234 & 12.00 & 8.54 & 8.99 \\
\hline 4 & 7.5040 & 7.0441 & 11.80 & 3.82 & 8.64 \\
\hline 5 & 4.3944 & 4.0887 & 9.50 & 4.19 & 7.99 \\
\hline 6 & 8.3288 & 7.9692 & 12.00 & 4.87 & 8.99 \\
\hline 7 & 4.5468 & 4.2189 & 9.61 & 4.31 & 8.00 \\
\hline 8 & 6.2270 & 5.8084 & 11.03 & 3.79 & 8.65 \\
\hline 9 & 8.6165 & 8.4352 & 12.00 & 5.54 & 9.00 \\
\hline 10 & 7.2679 & 6.8131 & 11.62 & 4.05 & 8.55 \\
\hline
\end{tabular}

Table 4.3 A few set optimal decision process parameters and their corresponding objective values of Developed 3 axes microEDM

\begin{tabular}{|c|c|c|c|c|c|}
\hline S. No & $\begin{array}{c}\text { MRR } \\
(\boldsymbol{\mu g} / \mathbf{s})\end{array}$ & $\begin{array}{c}\text { TWR } \\
(\boldsymbol{\mu g} / \mathbf{s})\end{array}$ & $\begin{array}{c}\text { Current } \\
(\mathbf{A})\end{array}$ & $\begin{array}{c}\text { Pulse On } \\
\text { Time }(\boldsymbol{\mu s})\end{array}$ & $\begin{array}{c}\text { Pulse Off } \\
\text { Time }(\boldsymbol{\mu s})\end{array}$ \\
\hline 1 & 11.0179 & 11.2375 & 12.00 & 8.97 & 8.99 \\
\hline 2 & 3.1531 & 2.3391 & 7.28 & 4.74 & 5.44 \\
\hline 3 & 9.5708 & 9.0548 & 11.92 & 7.21 & 8.54 \\
\hline
\end{tabular}




\begin{tabular}{|c|c|c|c|c|c|}
\hline 4 & 10.3990 & 10.2248 & 11.98 & 8.13 & 8.91 \\
\hline 5 & 3.8468 & 2.8588 & 8.53 & 4.99 & 7.19 \\
\hline 6 & 10.4611 & 10.6213 & 11.76 & 8.98 & 8.83 \\
\hline 7 & 8.9521 & 8.3608 & 11.76 & 7.04 & 7.92 \\
\hline 8 & 7.9337 & 7.0595 & 11.55 & 5.92 & 7.66 \\
\hline 9 & 7.2256 & 6.4528 & 10.90 & 6.91 & 7.37 \\
\hline 10 & 8.1585 & 7.3403 & 11.57 & 6.25 & 7.80 \\
\hline
\end{tabular}

\section{CONCLUSION}

A low cost three axes microEDMmachine has been developed indigenously consists of various components such as machining chamber, $\mathrm{X}-\mathrm{Y}$ table, tool feed and tool holder assembly, dielectric circulation system, power supply and automatic driving devices to control the spark gap distance. On the Z-axis the setup is capable of performing the $8 \mu \mathrm{m}$. Stainless Steel 316L was chosen as work piece along with $300 \mu$ mtungsten electrode with process parameters such as Current, Pulse on time and Pulse off time and studied the performance of MRR and TWR on both developed machine as well as the commercial machine. Due to the effective spark gap circuit developed with the use of hall current sensor the developed machine results reveals that $6.52 \%$ higher MRR and $26.10 \%$ Lower TWR is obtained. On applying the Response Surface Methodology, the mathematical model was developed and employed non-dominated Genetic algorithm to find the optimal process parameters. The optimum higher MRR and lower TWR was found to be $10.14 \%$ and $33.12 \%$ respectively for the developed machine. Hence, we can commercially this technology to the manufacturing industries for micro machining at lower cost.

\section{REFERENCES}

[1] Mahendran, S, Devarajan, R, Nagarajan, T, Majdi, A. "A review of microEDM", Proceedings of the International MultiConference of Engineers and Computer Scientists, 2010.

[2] Richard, J., Demellayer, R. "Micro-EDM-milling Development of new machining technology for micro-machining", Procedia CIRP 6, pp. 292 - 296, 2013.

[3] Bragança, MF, Rosa, AR, Dias, FM, Martins, AF., Alves, LL. "Experimental study of micro electrical discharge machining discharges", Journal of Applied Physics 113 (23), pp. 233301 (1-14), 2013.

[4] Karthikeyan, G, Ramkumar, J, Dhamodaran, S., Aravindan, S., "Micro electric discharge milling process performance: an experimental investigation", International Journal of Machine Tools \& Manufacture 50 (8), pp. 718 - 727, 2010.

[5] Kibria, G, Sarkar, BR, Pradhan, BB., Bhattacharyya, B. "Comparative study of different dielectrics for micro-EDM performance during microhole machining of Ti-6Al-4V alloy", The International Journal of Advanced Manufacturing Technology48, (5 - 8), pp. $557-570,2010$.

[6] Dhanabalan, S, Sivakumar, K., Sathiyanarayanan, C. "Optimization of EDM process parameters with multiple performance characteristics for Titanium Grades", European Journal of Scientific Research 68 (3), pp. 297 - 305, 2012. 
[7] Kadirvel, A, Hariharan, P., Gowri, S. "Experimental investigation on the electrode specific performance in Micro-EDM of Die-steel", Materials and Manufacturing Processes 28 (4), pp. 390 - 396, 2013.

[8] Pay Jun Liew, Jiwang Yan, Kuriyagawa, T. "Fabrication of deep micro-holes in reaction-bonded $\mathrm{SiC}$ by ultrasonic cavitation assisted micro-EDM", International Journal of Machine Tools and Manufacture 76, pp. 13 - 20, 2014.

[9] Sabur, A, Moudood, A, Ali, MY., Maleque, MA. "Effect of Micro-EDM parameters on material removal rate of nonconductive $\mathrm{ZrO} 2$ ceramic", Applied Mechanics and Materials 465 - 466, pp. 1329 - 1333, 2014.

[10] Kung, KY, Horng, JT., Chiang, KT. "Material removal rate and electrode wear ratio study on the powder mixed electrical discharge machining of cobalt-bonded tungsten carbide", International Journal of Advanced Manufacturing Technology 40 (1 - 2), pp. 95 - 104, 2009.

[11] Durillo, J, Garca, J, Nebro, A, Coello, C, Luna, F., Alba, E. "Multi-objective particle swarm optimizers: An experimental comparison", 5th International Conference on Evolutionary MultiCriterion Optimization, pp. 495 - 509, 2009.

[12] Somashekhar, KP., Ramachandran, N. J. "Optimization of material removal rate in micro-EDM using artificial neural network and genetic algorithms", Materials and Manufacturing Processes 25 (6), pp. 467 - 475, 2010.

[13] Mohamad, AB, Siddique, AN, Quadir, GA, Khan, ZA. Saini, VK. "Optimization of EDM parameters using Taguchi method", Proceeding of International Conference on Applications and Design in Mechanical Engineering, 2012.

[14] Pushpendra, S. B., Maheshwari, S., Sharma, C. "Multi-objective optimization of electric-discharge machining process using controlled elitist NSGA-II", Journal of Mechanical Science and Technology 26 (6), pp. 1875 - 1883, 2012.

[15] Praloy, S. D., Mishra "An improvement on NSGA-II for finding fast the better optimal solution in multi-objective optimization problem", Advances in Intelligent Systems and Computing 308, pp. 105 - 116, 2015.

[16] Phillip J Ross, "Taguchi Techniques for Quality Engineering” (2nd ed.), Tata McGraw Hill, New Delhi, 2005.

[17] Goldberg, DE. "Genetic Algorithms in search, Optimization \& Machine Learning", Addison-Wesley, Indianapolis, 1989.

[18] Khadar, B.S., Jagannadha, R.M., Murahari, K.O.L.L.I. "Multi-Objective Optimization of Process Parameters for Powder Mixed Electrical Discharge Machining of Inconel X750 Alloy Using Taguchi-Topsis Approach", Strojnícky časopis - Journal of Mechanical Engineering 71(1), pp.1 - 18, 2021. DOI: 10.2478/scjme-2021-0001

[19] Manoj, M. et al. "Effect of machine feed rate on kerf-width, material removal rate, and surface roughness in machining of $\mathrm{Al} / \mathrm{SiC}$ composite material with wire electrical discharge machine", Strojnícky časopis - Journal of Mechanical Engineering 70 (1), pp. 81 - 88, 2020. DOI: $10.2478 /$ scjme-2020-0008

[20] Dwaipayan, D., Titas, N., Bandyopadhyay, A. "Parametric study for wire cut electrical discharge machining of sintered titanium." Strojnícky časopis - Journal of Mechanical Engineering 69 (1), pp. 17 - 38, 2019. DOI: 10.2478/scjme-2019-0002 